\title{
EXPLAINING EXTREME EVENTS OF 2018 From a Climate Perspective
}
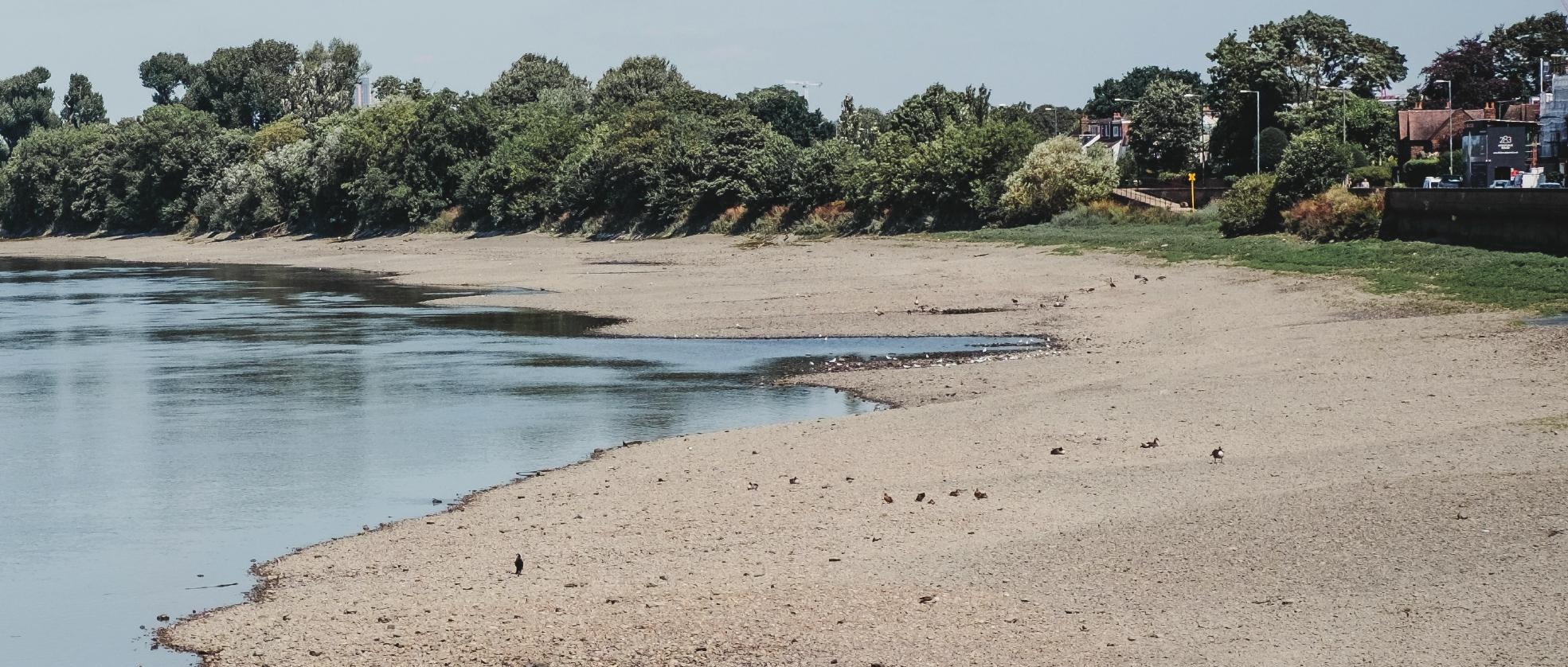

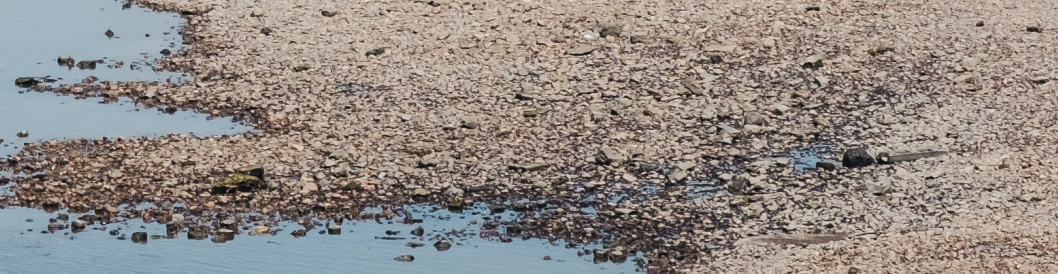

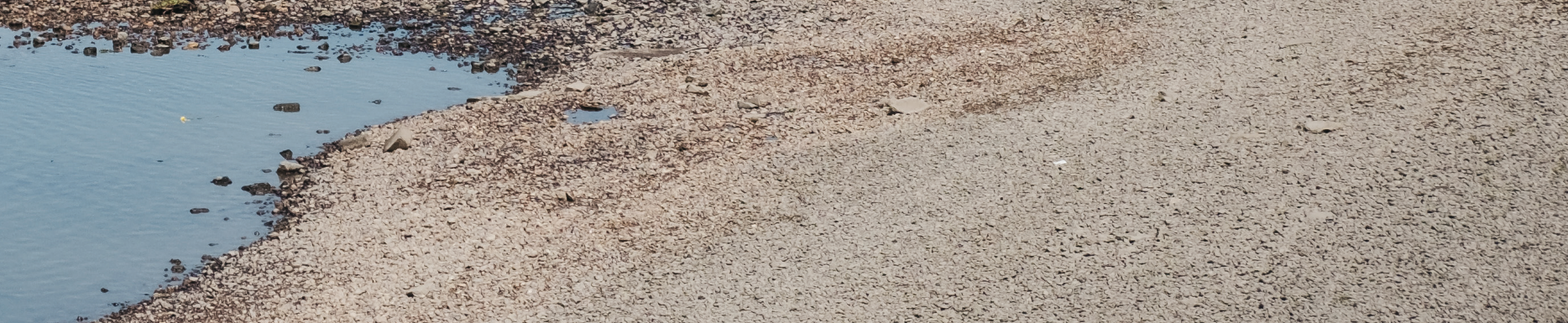

$x^{2}+m^{3}$

1.

Special Supplement to the Bulletin of the American Meteorological Society

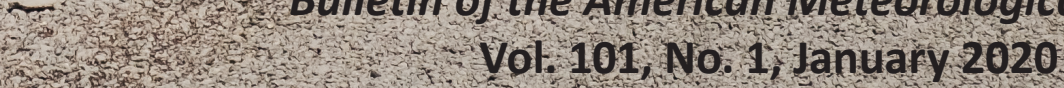




\title{
EXPLAINING EXTREME EVENTS OF 2018 FROM A CLIMATE PERSPECTIVE
}

\author{
Editors \\ Stephanie C. Herring, Nikolaos Christidis, Andrew Hoell, \\ Martin P. Hoerling, and Peter A. Stott
}

\section{BAMS Special Editors for Climate \\ Andrew King, Thomas Knutson, \\ John Nielsen-Gammon, and Friederike Otto}

Special Supplement to the

Bulletin of the American Meteorological Society

Vol. I OI, No. I, January 2020

American Meteorological Society 
CORRESPONDING EDITOR:

Stephanie C. Herring, PhD

NOAA National Centers for Environmental Information

325 Broadway, E/CC23, Rm IB-I3|

Boulder, CO, 80305-3328

E-mail: stephanie.herring@noaa.gov

Cover CReDit: iStock.com/Alena Kravchenko-River Thames receded during a heatwave in summer 2018 in London, United Kingdom.

\section{HOW TO CITE THIS DOCUMENT}

Citing the complete report:

Herring, S. C., N. Christidis, A. Hoell, M. P. Hoerling, and P. A. Stott, Eds., 2020: Explaining Extreme Events of 2018 from a Climate Perspective. Bull. Amer. Meteor. Soc., I0I (I), SI-SI28, doi:I0.II75/BAMS-ExplainingExtremeEvents20I8.I.

Citing a section (example):

Mahoney, K., 2020: Extreme Hail Storms and Climate Change: Foretelling the Future in Tiny, Turbulent Crystal Balls? [in "Explaining Extremes of 2018 from a Climate Perspective"]. Bull. Amer. Meteor. Soc., I0I (I), SI7-S22, doi:I0.II75/BAMSD-19-0233.I. 


\section{TABLE OF CONTENTS}

I. The Extreme 2018 Northern California Fire Season. . . . . . . . . . . . . . . . . . . I

2. Anthropogenic Impacts on the Exceptional Precipitation of 2018

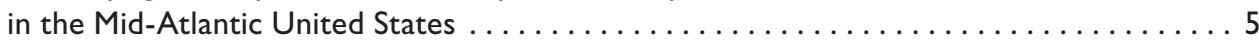

3. Quantifying Human-Induced Temperature Impacts on the 2018 United States Four Corners Hydrologic and Agro-Pastoral Drought . . . . . . . . . . . . . . I

4. Extreme Hail Storms and Climate Change: Foretelling the Future in Tiny, Turbulent Crystal Balls? . . . . . . . . . . . . . . . . . . . . . . . . . . . . . . . . . 17

5. The Extremely Cold Start of the Spring of 2018 in the United Kingdom . . . . . . . . . 23

6. The Exceptional Iberian Heatwave of Summer $2018 \ldots \ldots \ldots \ldots \ldots \ldots . \ldots . \ldots . \ldots 29$

7. Analyses of the Northern European Summer Heatwave of $2018 \ldots \ldots \ldots \ldots \ldots \ldots . \ldots 35$

8. Anthropogenic Influence on the 2018 Summer Warm Spell in Europe:

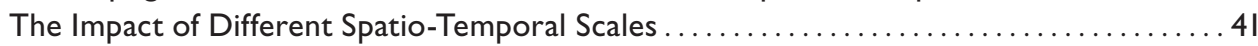

9. On High Precipitation in Mozambique, Zimbabwe and Zambia in February 2018 . . . . . 47

10. The Record Low Bering Sea Ice Extent in 2018: Context, Impacts, and an Assessment of the Role of Anthropogenic Climate Change ............. 53

II. The Late Spring Drought of 2018 in South China...................... 59

12. Anthropogenic Influence on 2018 Summer Persistent Heavy Rainfall

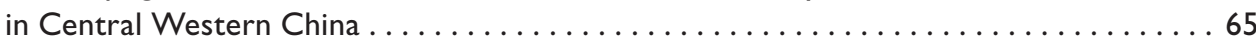

13. Conditional Attribution of the 2018 Summer Extreme Heat over Northeast China: Roles of Urbanization, Global Warming, and Warming-Induced Circulation Changes .... . 7I

14. Effects of Anthropogenic Forcing and Natural Variability on the 2018 Heatwave in Northeast Asia. . . . . . . . . . . . . . . . . . . . 77

15. Anthropogenic Influences on the Persistent Night-Time Heat Wave in Summer 2018 over Northeast China . . . . . . . . . . . . . . . . . . . . . . 83

16. Anthropogenic Contributions to the 2018 Extreme Flooding over the Upper Yellow River Basin in China . . . . . . . . . . . . . . . . . . . . . . . . . . 89

17. Attribution of the Record-Breaking Consecutive Dry Days in Winter 2017/18

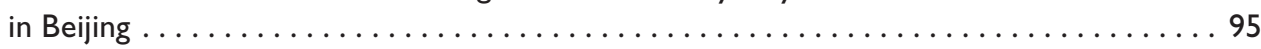

18. Quantifying Human Impact on the 2018 Summer Longest Heat Wave

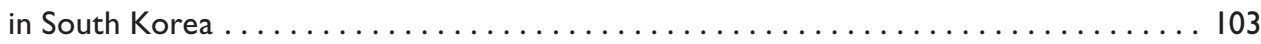

19. The Heavy Rain Event of July 2018 in Japan Enhanced by Historical Warming. . . . . . . 109

20. Deconstructing Factors Contributing to the 2018 Fire Weather in Queensland, Australia ...................................

21. A I-Day Extreme Rainfall Event in Tasmania: Process Evaluation and Long Tail Attribution 


\title{
A I-DAY EXTREME RAINFALL EVENT IN TASMANIA: PROCESS EVALUATION AND LONG TAIL ATTRIBUTION
}

\author{
Carly R. Tozer, James S. Risbey, Michael R. Grose, Didier P. Monselesan, Dougal T. Squire, \\ amanda S. Black, Doug Richardson, Sarah N. Sparrow, Sihan li, and David Wallom
}

Attribution of an extreme magnitude I-day rainfall event in Hobart is inhibited by small sample size. For moderate magnitude Hobart daily rainfall extremes, models suggest that the associated extratropical lows will deliver more rainfall with weaker pressure anomalies in a warmer world.

0 n 10 May 2018, Hobart, Tasmania, experienced an extreme rainfall event, which caused flash flooding, infrastructure damage, and major disruption across the capital city, leading to $\$ 100$ million in insurance claims (Cooper 2019). Gauged records indicate that $130 \mathrm{~mm}$ of rain fell during the event, which ranks as the second highest autumn rainfall day over the $\sim 120$-yr record, with the largest occurring in 1960. The frequency and magnitude of daily autumn wet extremes show interannual to multidecadal variability over the gauged record and no clear linear trend (Fig. 1a). Future projections, however, indicate that in a warmer world these types of events are likely to increase in both frequency and magnitude across Tasmania (White et al. 2013). Given its extreme magnitude, we thus ask whether an anthropogenic contribution is already apparent in the autumn 2018 event.

Anthropogenic attribution assessments typically rely on general circulation models (GCMs) to characterize the expected signal. Daily rainfall extremes present a novel challenge for event attribu-

AfFiliations: Tozer, Risbey, Grose, Monselesan, SQuire, BLACK, AND RICHARDSON-CSIRO Oceans and Atmosphere, Hobart, Tasmania, Australia; SPARrow, LI, AND Wallom-Oxford e-Research Centre, Department of Engineering, University of Oxford, Oxford, United Kingdom.

CORRESPONDING AUTHOR: Carly Tozer, carly.tozer@csiro. au

DOI:10.1175/BAMS-D-19-0219.1

(C) 2020 American Meteorological Society

For information regarding reuse of this content and general copyright information, consult the AMS Copyright Policy. tion in GCMs because the rainfall process is at least partly parameterized. To have confidence in the use of GCMs for attribution studies, it is important to assess not only their ability to simulate the statistics of extreme events (e.g., magnitude and frequency) but also the associated atmospheric circulation (Grose et al. 2012; Otto 2016; Sillmann et al. 2017; Tozer et al. 2020). This provides confidence that a model is producing rainfall extremes for the right reasons (Eyring et al. 2019).

In our approach to this event attribution study we include an evaluation of our selected model's ability to simulate 1-day wet extremes in Hobart and their associated synoptic- and large-scale circulation. We utilize the atmosphere-only HadAM3P model from the weather@home project (Massey et al. 2015; Guillod et al.2017).Weather@home provides simulations of both an "actual" and "natural" world (effectively, with and without anthropogenic climate change), which allows us to estimate changes in climate extremes in the current climate relative to a climate unaltered by anthropogenic influence (Massey et al. 2015; Schaller et al. 2016; Black et al. 2016).

DATA AND METHODS. We use 450 simulations of autumn 2018 from the actual (ACT) and natural (NAT) weather@home experiments (equivalent to 40,500 days each). The ACT simulations are produced under 2018 sea surface temperatures (SSTs), sea ice concentrations, and atmospheric forcings. NAT uses preindustrial forcings and an SST field that has the estimated anthropogenic SST change pattern removed. This change pattern is derived from estimates from multiple GCMs contributing to CMIP5 (Schaller et al. 2016). We extract rainfall for the model grid box encompassing Hobart. Geopotential height anomalies at 
$500 \mathrm{hPa}$ (z500), calculated relative to the mean of all NAT or ACT autumn 2018 simulations, respectively, are used to represent the atmospheric circulation.

For observed rainfall we use a gridded rainfall product from the Australian Water Availability Project (AWAP). AWAP provides interpolated gauged data at a grid resolution of $0.05^{\circ}$ longitude $\times 0.05^{\circ}$ latitude (Raupach et al. 2006; Jones et al. 2009) from 1900 to present. To allow a fair comparison with the lowerresolution model, we spatially averaged all AWAP grid boxes within the relevant HadAM3P grid box $\left(1.875^{\circ}\right.$ longitude $\times 1.25^{\circ}$ latitude, inset Fig. 1b). We also refer to point data recorded in Hobart (Australian Bureau of Meteorology gauge 094029). The Japanese 55-Year Reanalysis (JRA: Kobayashi et al. 2015) is used as our observed reference for atmospheric circulation and is available from 1958 to the present.

Figure la presents the highest daily rainfall recorded in each autumn across the 1900-2018 period. The magnitudes of the highest autumn rainfall days in 1909, 1960, and 2018 far exceed those in other years. There is clearly a small sample of these "extreme" extremes, which makes attribution challenging. For the purposes of analysis we include "extreme" extremes (including the autumn 2018 event) as part of a broader range of 1-day extreme wet events (National Academies of Sciences, Engineering, and Medicine 2016; Bellprat et al. 2019). We identify 1-day extreme wet events in Hobart (in the AWAP, gauge, and model datasets) as any day greater than the 99 th percentile daily rainfall, where the 99th percentile value is calculated per calendar day, to account for the seasonal cycle. Daily rainfall series are noisy, so to provide a reasonable sample size from which to calculate the 99th percentile values, we use a moving 15-day window centered on the day in question (Perkins and Alexander 2013). For example, for calendar day 8 May, we include days from 1 May to 15 May across the 1900-2018 period in the analysis pool (i.e. close to 2,000 days). For the gauged record the threshold percentile values range from $\sim 18-27 \mathrm{~mm}$ across autumn days. For the AWAP extreme events the threshold values range from $\sim 16-31 \mathrm{~mm}$ and for modeled extremes this range is $\sim 10-22 \mathrm{~mm}$.

To evaluate the model simulations we compare the distributions of wet events identified in the model (ACT) with the AWAP and gauged data distributions (Fig. 1b). We then average the $\mathrm{z} 500$ anomalies associated with each wet event to form a composite of the circulation associated with wet events in Hobart in both the observations (in this case AWAP and JRA) and model (ACT) simulations. This approach is based on the methodology presented in Tozer et al. (2020).
For the event attribution component we assess both the rainfall and circulation associated with wet extremes in the ACT and NAT simulations. Specifically,

1) We identify 1-day wet events in NAT and ACT, with both cases referenced to the NAT percentile values. The NAT thresholds provide a baseline to determine any changes in the extreme rainfall distribution from the "natural" to the "actual" world.

2) We extract $\mathrm{z} 500$ anomalies for the model grid box approximately encompassing the highest negative z500 anomaly associated with wet events (as identified in the composite analysis). We assess the z500 anomaly distribution for NAT and ACT wet events to determine if there are changes in the intensity of z500 associated with wet events in a warming world.

RESULTS AND DISCUSSION. Model evaluation. We compare the magnitude of autumn 1-day wet events in the gauged, AWAP and model (ACT) data in Fig. 1b. For the gauged data, it is clear that (a) there is a large range of magnitudes that exceed the 99th percentile threshold; and (b) the extreme event distribution has a long tail (i.e., few high-magnitude extremes). Most events range between 20 and $50 \mathrm{~mm}$ (median of $29 \mathrm{~mm}$ ) and occur at a frequency of almost one event per year. The autumn 2018 event sits far in the tail of the distribution. The AWAP wet events have a slightly higher median of $31 \mathrm{~mm}$ but have reduced extreme magnitudes relative to the gauged data (e.g., the autumn 2018 event sits in the $70-80$-mm range), a result of the spatial averaging (discussed above), and because it is a gridded product (Tozer et al. 2012; King et al. 2013). The modeled wet events have further reduced magnitude with a median value of $21 \mathrm{~mm}$.

Both AWAP and the model have a slightly lower frequency of wet events relative to gauged. Common across all datasets is the long tail of the wet event magnitude distribution, highlighting that there are very few "extreme" extremes in both observations and large model simulations.

As seen in Fig. 1c, Hobart 1-day wet events are typically associated with an intense low pressure system (Fox-Hughes and White 2015), which is cut off from the westerly flow by a blocking high in the Tasman Sea (Pook et al. 2010). These synoptic structures are associated with a large-scale wave train in the polar jet (Tozer et al. 2018). Figure 1d indicates that the model successfully captures these synoptic and large-scale processes, which builds confidence in 

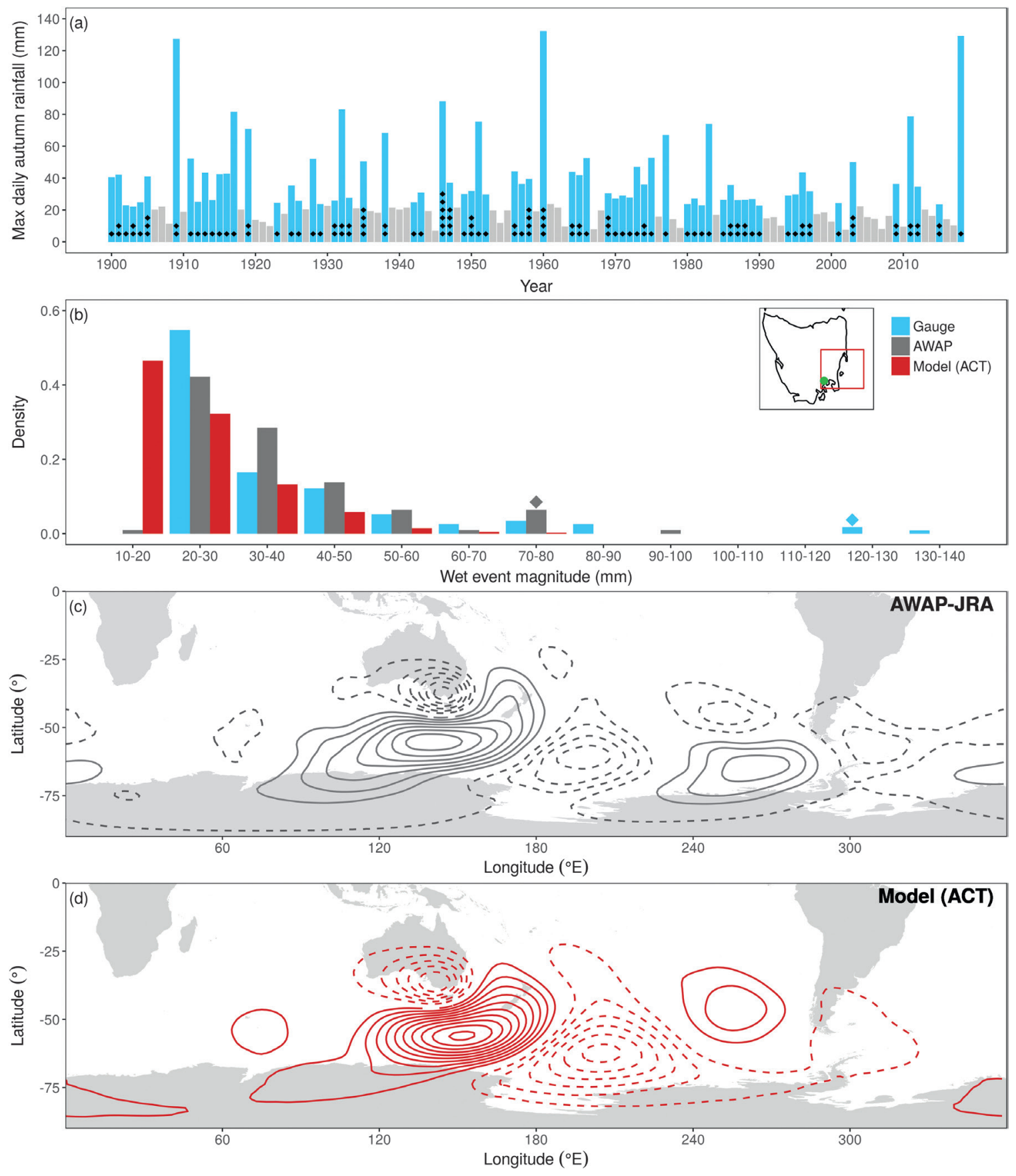

Fig. I. Model evaluation. (a) Maximum daily rainfall in each autumn in Hobart (Ellerslie Rd., gauge no. 094029). Blue bars indicate that the rainfall event is classed as a wet event as per the shifting window method described in section 2. Years without any daily wet extreme events are indicated in gray. The number of wet events occurring in each year is shown with black dots (e.g., 3 dots means 3 wet events occurred that year). Linear trend analysis found no significant trend in the magnitude of the maximum daily autumn rainfall ( $p$ value $=0.25$ ) or the number of extreme daily wet events ( $p$ value $=0.4 \mathrm{I}$ ) over the gauged record. (b) Histogram of gauged (blue bars), AWAP (gray bars) and modeled (ACT; red bars) wet events. Diamonds indicate where the autumn 2018 event sits in the gauged and AWAP distributions. Gauged and AWAP analyses performed over the 1900-2018 period. 450 autumn 2018 ACT simulations were used for the model analysis, with ACT wet events identified relative to ACT percentiles. Inset shows the location of Hobart (green dot) and relevant model grid box (red square). (c) Composite of JRA z500 anomalies for AWAP derived wet events in Hobart region. Solid (dashed) contours indicate positive (negative) geopotential height anomalies with contours every $15 \mathrm{~m}$. (d) As in (c), but using modeled ACT (red contours). 
its representation of real-world wet extremes for the following attribution assessment.

Event attribution. The NAT and ACT wet event magnitude histograms have similar shapes (Fig. 2a), with a Kolmogorov-Smirnoff (KS) test suggesting that there is no significant difference between the histograms at the $5 \%$ level ( $p$ value of 0.18 ). As in the observations, the NAT and ACT extreme event distributions have a long tail. Also of interest is that while the overall number of wet extremes in NAT and ACT are similar, there is a higher number of events in the $30-50-\mathrm{mm}$ range in ACT. Figure $2 \mathrm{c}$ presents the return period of daily rainfall in NAT and ACT. Again it is clear that there are very few days with rainfall $>50 \mathrm{~mm}$ in both simulations. The confidence intervals for NAT and ACT for these high-magnitude rainfall days are both large and overlapping. These results show that even in a large number of model simulations, these "extreme" extremes are very rare in Hobart. We cannot draw statistically robust conclusions about the anthropogenic influence on the autumn 2018 event from only a handful of events of that size. Some comment may be made about events in the $30-50-\mathrm{mm}$ range ("midrange" extremes) given their larger sample size. Figure $2 c$ clearly shows that return periods for rain days in this range are lower in ACT relative to NAT (i.e., rain days of this magnitude are more frequent in ACT). For example, a 35-mm rainfall day in ACT has a return period of $\sim 8.5 \mathrm{yr}$ relative to $\sim 13 \mathrm{yr}$ in NAT (Fig. $2 \mathrm{c}$ inset).

We now assess variability in the intensity of the low pressure systems associated with Hobart wet events (Fig. 2d). There is a clear displacement of probability mass toward lower magnitude (i.e., less negative) z500 anomalies for ACT events in Fig. 2c relative to NAT. This suggests that wet events in ACT can occur in association with a weaker cutoff low intensity, which is also evident in the composite ACT and NAT circulations (Fig. 2b). A KS test indicates that the shift in the distributions is significant at the $5 \%$ level ( $p$ value of 0.02 ).

We further explore this observation in Fig. 2e. Here we focus on the z500 anomaly range in which the majority of the wet extremes occur (i.e., 0 to $-200 \mathrm{~m}$; Fig. 2d) and plot the distribution of wet extreme magnitude for z500 anomalies in bins spanning $10 \mathrm{~m}$ each. Figure $2 \mathrm{e}$ reveals a tendency for wet extreme magnitudes in ACT to be greater than NAT for the same z500 anomaly, particularly in the -160 - to $-90-\mathrm{m}$ z500 anomaly range. These results thus indicate that wet extremes in ACT occur in association with reduced (i.e., less negative) pressure anomalies relative to NAT or, alternately, for the same size pressure anomaly there is a tendency for higher magnitude wet events in ACT relative to NAT. These results lend support to the idea that extratropical baroclinic eddies (e.g., cutoff lows) may be weaker in a warmer climate (e.g., as represented here by the ACT world), but more efficient in that the increased moisture in the atmosphere makes for more intense rainfall extremes (Held 1993; Schneider et al. 2010).

CONCLUSIONS. We have examined whether the autumn 2018 extreme 1-day rainfall event in Hobart had an apparent anthropogenic contribution. We first undertook a process evaluation of the HadAM3P model and found that although modeled wet events tend to have lower magnitudes compared to observed, the associated atmospheric circulation is well captured in the model, which gives confidence in its use in this attribution study.

Based on the assessment of ACT and NAT simulations from the weather@home project,we draw no clear conclusions (either way) about the anthropogenic influence on very extreme rainfall days (like the autumn 2018 event), given the very small sample size of events of this magnitude. There are, however, indications in the model simulations that moderate magnitude 1-day wet extremes in Hobart in a warmer world (represented here by the ACT simulations) are associated with higher rainfall magnitudes for the same or weaker (i.e., less negative) circulation anomalies. To provide further confidence that extratropical lows are becoming more efficient in delivering extreme rainfall events both in Hobart and more generally, additional models, seasons and study regions should be tested.

ACKNOWLEDGMENTS. Thank you to Paola Petrelli (University of Tasmania) for providing access to the weather@home dataset. This work was supported by the Decadal Climate Forecast Project, DIGISCAPE Future Science Platform at CSIRO, Hydro Tasmania and the National Environmental Science Program's Earth Systems and Climate Change Hub.

\section{REFERENCES}

Bellprat, O., V. Guemas, F. Doblas-Reyes, and M. G. Donat, 2019: Towards reliable extreme weather and climate event attribution. Nat. Commun., 10, 1732, https://doi.org/10.1038/s41467-019-09729-2.

Black, M. T., and Coauthors, 2016: The weather@home regional climate modelling project for Australia and New Zealand. Geosci. Model Dev., 9, 3161-3176, https://doi.org/10.5194/gmd-9-3161-2016. 

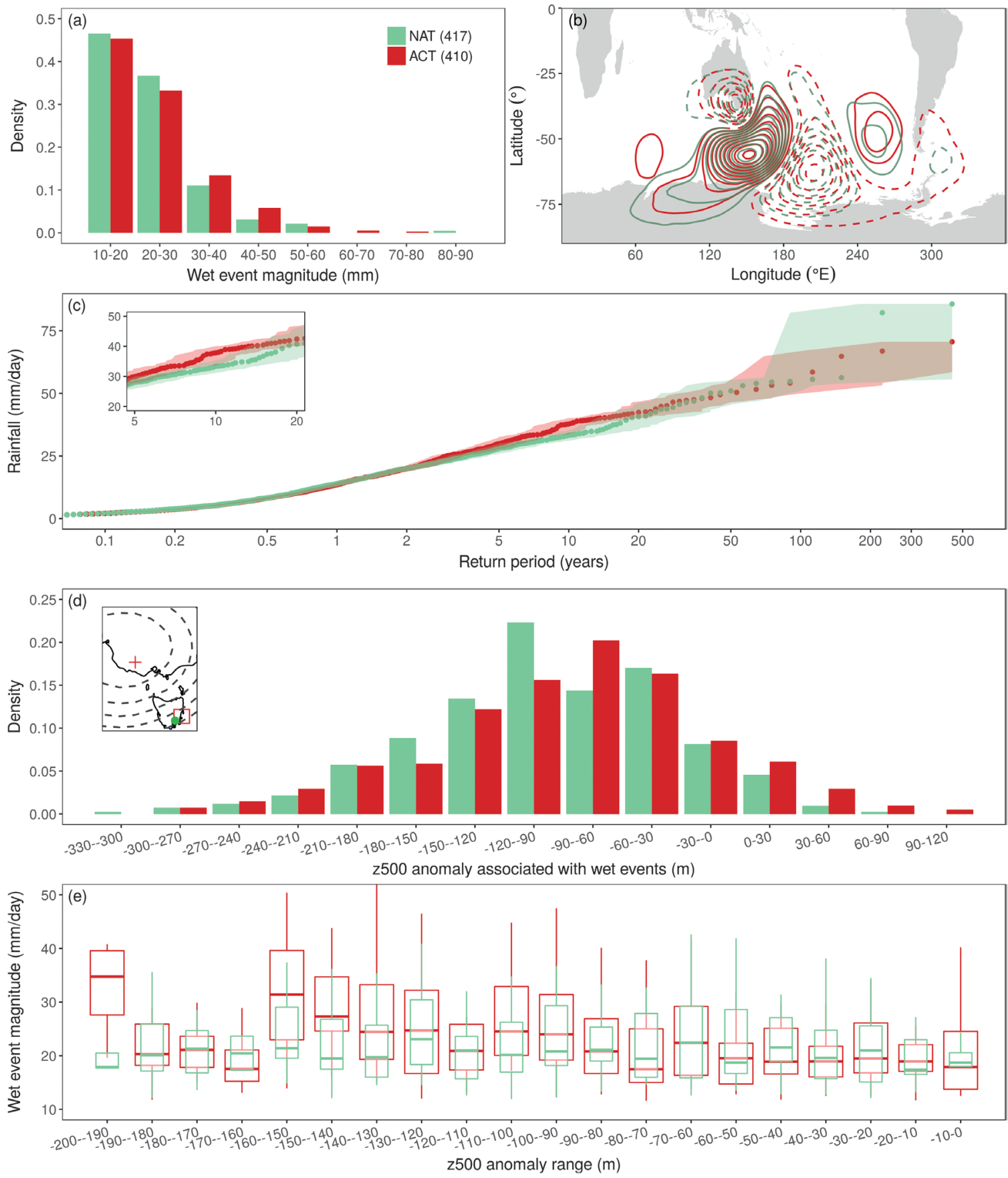

Fig. 2. Event attribution. (a) Histogram of NAT (green) and ACT (red) wet event magnitude. Wet events in NAT and ACT identified relative to the NAT percentiles. Bracketed numbers show number of wet events identified for each dataset. NAT wet event thresholds ranged from 9.5-21.5 mm and for ACT 9.6-21.9 $\mathrm{mm}$. (b) NAT (green contours) and ACT (red contours) wet extreme composite z500 patterns. The mean $\mathrm{z} 500$ anomaly for the selected model grid point locating the cutoff low [red cross in inset in (d)] in ACT is $\mathbf{- 8 5 . 6} \mathrm{m}$ compared with $-\mathbf{9 6 . 6}$ for NAT. (c) Return period (autumns) for NAT and ACT daily rainfall. Shaded areas indicate the $95 \%$ confidence interval using bootstrap resampling. Inset zooms in on selected rainfall and return period range. (d) NAT and ACT z500 anomalies associated with wet events for selected model grid point (red cross in inset). (e) Boxplots of NAT and ACT wet event magnitude for different negative $\mathrm{z} 500$ anomaly ranges. The boxes indicate the 25 th and 75 th percentile range. The solid bars across the boxes indicate the median. Whiskers indicate the 5th and 95th percentile. Note that for all figures NAT is represented by the color green and ACT by the color red. 
Cooper, E., 2019: Tasmania’s \$100m floods still affecting homes and businesses one year on. Australian Broadcasting Corporation, 9 May 2019, https://www. abc.net.au/news/2019-05-09/tas-hobart-floods-oneyear-on/11091120.

Eyring, V., and Coauthors, 2019: Taking climate model evaluation to the next level. Nat. Climate Change, 9, 102-110, https://doi.org/10.1038/s41558-018-0355-y.

Fox-Hughes, P., and C. J. White, 2015: A synoptic climatology of heavy rainfall in Hobart. 36th $\mathrm{Hy}$ drology and Water Resources Symposium: The Art and Science of Water, Hobart, Tasmania, Engineers Australia, 1010.

Grose, M. R., M. J. Pook, P. C. McIntosh, J. S. Risbey, and N. L. Bindoff, 2012: The simulation of cutoff lows in a regional climate model: Reliability and future trends. Climate Dyn., 39, 445-459, https://doi.org/10.1007/ S00382-012-1368-2.

Guillod, B. P., and Coauthors, 2017: weather@home 2: Validation of an improved global-regional climate modelling system. Geosci. Model Dev., 10, 1849-1872, https://doi.org/10.5194/gmd-10-1849-2017.

Held, I. M., 1993: Large-scale dynamics and global warming. Bull. Amer. Meteor. Soc., 74, 228-242, https://doi.org/10.1175/1520-0477(1993)074<0228:LS DAGW $>2.0 . \mathrm{CO} ; 2$.

Jones, D. A., W. Wang, and R. Fawcett, 2009: Highquality spatial climate data-sets for Australia. Aust. Meteor. Oceanogr. J., 58, 233-248, https://doi. org/10.22499/2.5804.003.

King, A. D., L. V. Alexander, and M. G. Donat, 2013: The efficacy of using gridded data to examine extreme rainfall characteristics: A case study for Australia. Int. J. Climatol., 33, 2376-2387, https://doi. org/10.1002/joc.3588.

Kobayashi, S., and Coauthors, 2015: The JRA-55 reanalysis: General specifications and basic characteristics. J. Meteor. Soc. Japan, 93, 5-48, https://doi. org/10.2151/JMSJ.2015-001.

Massey, N., and Coauthors, 2015: weather@home-Development and validation of a very large ensemble modelling system for probabilistic event attribution. Quart. J. Roy. Meteor. Soc., 141, 1528-1545, https:// doi.org/10.1002/qj.2455.

National Academies of Sciences, Engineering, and Medicine, 2016: Attribution of Extreme Weather Events in the Context of Climate Change. The National Academies Press, 186 pp.

Otto, F., 2016: The art of attribution. Nat. Climate Change, 6, 342-343, https://doi.org/10.1038/nclimate2971.
Perkins, S. E., and L. V. Alexander, 2013: On the measurement of heat waves. J. Climate, 26, 4500-4517, https://doi.org/10.1175/JCLI-D-12-00383.1.

Pook, M., J. Risbey, and P. McIntosh, 2010: East coast lows, atmospheric blocking and rainfall: A Tasmanian perspective. IOP Conf. Ser.: Earth Environ. Sci., 11, 012011, https://doi.org/10.1088/17551315/11/1/012011.

Raupach, M. R., C. M. Trudinger, P. R. Briggs, and E. A. King, 2006: Australian water availability project. Tech. Rep., Commonwealth Scientific and Industrial Research Organisation, 56 pp, http://www.cmar. csiro.au/e-print/open/raupachmr_2006d.pdf.

Schaller, N., and Coauthors, 2016: Human influence on climate in the 2014 southern England winter floods and their impacts. Nat. Climate Change, 6, 627-634, https://doi.org/10.1038/nclimate2927.

Schneider, T., P. A. O’Gorman, and X. J. Levine, 2010: Water vapor and the dynamics of climate changes. Rev. Geophys., 48, RG3001, https://doi. org/10.1029/2009RG000302.

Sillmann, J., and Coauthors, 2017: Understanding, modeling and predicting weather and climate extremes: Challenges and opportunities. Wea. Climate Extremes, 18, 65-74, https://doi.org/10.1016/j. wace.2017.10.003.

Tozer, C. R., A. S. Kiem, and D. C. Verdon-Kidd, 2012: On the uncertainties associated with using gridded rainfall data as a proxy for observed. Hydrol. Earth Syst. Sci., 16, 1481-1499, https://doi.org/10.5194/ hess-16-1481-2012.

—, J. S. Risbey, T. J. O. Kane, D. P. Monselesan, and M. J. Pook, 2018: The relationship between wave trains in the Southern Hemisphere storm track and rainfall extremes over Tasmania. Mon. Wea. Rev., 146, 4201-4230, https://doi.org/10.1175/MWRD-18-0135.1.

- — - D. P. Monselesan, D. T. Squire, M. A. Chamberlain, R. J. Matear, and T. Ziehn, 2020: Assessing the representation of Australian regional climate extremes and their associated atmospheric circulation in climate models. J. Climate, 33, 12271245, https://doi.org/10.1175/JCLI-D-19-0287.1.

White, C. J., K. L. McInnes, R. P. Cechet, S. P. Corney, M. R. Grose, G. K. Holz, J. J. Katzfey, and N. L. Bindoff, 2013: On regional dynamical downscaling for the assessment and projection of temperature and precipitation extremes across Tasmania, Australia. Climate Dyn., 41, 3145-3165, https://doi.org/10.1007/ S00382-013-1718-8. 